\title{
Niche Overlap between Pongo pygmaeus wurmbii and Helarctos malayanus Raffles within Small Scale Habitat in Punggualas Area, Sebangau National Park
}

\author{
Adventus Panda, Widya Krestina \\ Department of Biology, Faculty of Mathematics and Natural Sciences, University of Palangka Raya, Palangka \\ Raya 7311A, Indonesia
}

Article history:

Submission August 2019

Revised November 2019

Accepted May 2020

*Corresponding author:

E-mail: apanda@mipa.upr.ac.id

\begin{abstract}
The Sebangau National Park is a major stronghold for Bornean Orangutan (Pongo pygmaeus wurmbii) ranging from 6000 - 9000 individuals. In comparison with Bornean Orangutans, very little ecological fieldwork has been conducted to investigate sun bear biology, and there have been no thorough surveys of distribution or population densities. Thus, this study aimed to investigate the basic information on niche overlap between these two endangered species, specifically to quantify their relationship within the small-scale habitat in Punggualas area, SNP. Data was collected and measured during 15 - 21 June 2019; using line transects methods. A total of $6580 \mathrm{~m}$ was walked along 8 consecutive transects. Bear and aging sign follow Augeri protocols. A total 18 printed mark-claw and 17 Orangutan nests was measured according to the mentioned methodology. The relationships between signs use binary logistic regressions (StatPlus for Mac) and PCA model (using R), while interspecific relationships use Co-Occurrence modeling, ESP for Windows. The results showed that there is no difference between bear sign and orangutan nest ( $\chi^{2}: 26.249$; df $: 1$, p-value : 0.001$)$; While the results on habitat selection between transects is failed to reject the null hypothesis $\left(\chi^{2}=0.29\right.$; $\mathrm{df}: 1$, p-value : 0.490 ). The Mann-Whitney U test, also confirmed no distinctive overlap between the Orangutan and the Sun Bear (Z: 0.84; p-value: 0.40). The co-occurrence simulations also revealed significant results $(\mathrm{C}-\mathrm{Score}=1.00)$, by means both target animals co-existed in the habitat. Obviously, the Orangutan and Sun Bear occupy the same habitat. There is no distinctive overlap between them in terms of tree species selection and having a close interrelationship in terms of feeding ground, whereas the fruiting is not available. The only distinctive difference is that the Bear sign was tend hindering waterlogged terrain.
\end{abstract}

Keywords: Helarctos malayanus Raffles, Niche overlap, Pongo pygmaeus wurmbii, Punggualas, Sebangau National Park

\section{Introduction}

The Sebangau catchment area is in Central Kalimantan (Indonesian part of Borneo Island) and lies between the rivers Katingan and Sebangau and covers approximately $9200 \mathrm{~km}^{2}$. In October 2004, about 578,800 ha in the western part of this region were officially protected and gazetted as the Sebangau National Park (SNP). The Park (Figure 1) is mostly covered with peat swamp forests in which five major forest types can be described [1, 2, 3, 4]. It is a major stronghold for Bornean Orangutan (Pongo pygmaeus wurmbii) ranging from 6000 - 9000 individuals [5, 6]. Although there was no publication on Sun Bear population in SNP, the park is also an important habitat for Malayan Sun Bear (Helarctos malayanus Raffles). During the Orangutan population study in 2006 to 2007, this animal proof of presence, such as printed claw-marked, often spotted along transects. Logging concessions were allocated within Sebangau until 1997. After the cessation of commercial logging, illegal logging started at an unprecedented scale. In addition to illegal logging, 


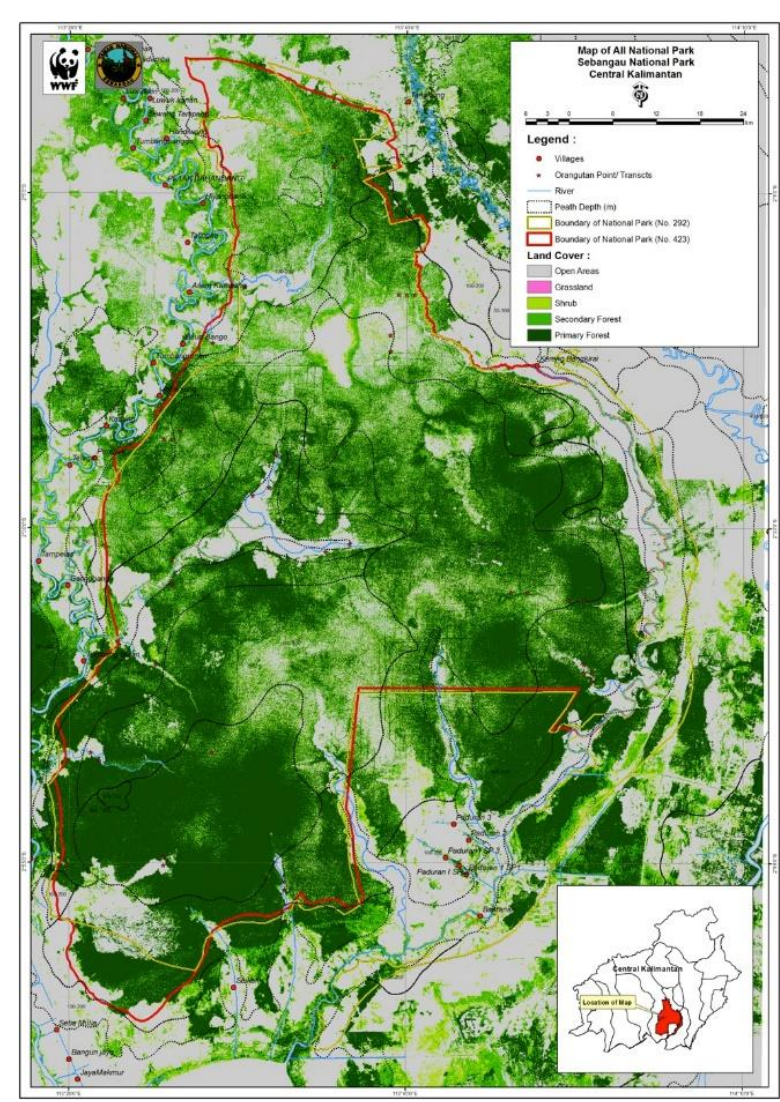

Figure 1. Forest Cover Density (FCD) map of Sebangau National Park, (source : WWFIndonesia, 2011).

extensive fires have repeatedly hit this area (2002, 2007, 2009, 2015, and 2019).

According to 2011 observations data, within 12 plots $(20 \times 20 \mathrm{~m})$ in Punggualas area, Sebangau National Park, we have documented dominant top ten families such as Euphorbiaceae, Anacardiaceae Myristicaceae, and Ebenaceae [5]. Invertebrates such as termites (Isoptera), beetles including larvae of Coleoptera, and beetle larvae were the predominant food items, occurring in 57\% of the scat samples. Figs (Ficus sp.) were the most common fruit consumed (in $61 \%$ of the samples) during the non-fruiting season. Vertebrates were also consumed but less commonly. Most feeding sites $(60 \%)$ were in decaying wood, where sun bears foraged for termites, beetles, and beetle's larvae. Tree cavities with bee nests and decaying standing stumps were also recorded as feeding sites. [7], concluded that sun bears are opportunistic omnivores consuming a wide variety of food items. In comparison with Bornean Orangutans, very little ecological fieldwork has been conducted to investigate sun bear biology, and there have been no thorough surveys of distribution or population densities [8, 9]. Furthermore, [10] have reported lack of biological information on the Sun Bear is a serious limitation to conservation efforts. Therefore basic research on sun bears is the highest priority for any bear species worldwide. Thus, this study aimed to investigate the basic information on niche overlap between these two endangered species, precisely to quantify their relationship within the small-scale habitat in Punggualas area, SNP.

\section{Material and Methods}

The study was conducted within the Punggualas research site, managed by WWF-Indonesia Central Kalimantan (Figure 2), during 15 - 21 June 2019.

\section{Line transects}

Distance sampling uses straight "line transects" to record the presence of objects (animals themselves or their signs, such as nests). Except near the centerline or center point, there is no assumption that all objects are detected. This assumption is of special importance in tropical rainforest where the probability of detecting an object decreases rapidly with increasing distance from the observer. Transect length was directly determined with a walking-distance measurer. Each nest observed was tagged.

Species of the nesting tree, as well as the approximate nest's age, classified according to five successional stages: A - new: presence of green leaves; B - recent: all leaves dry and brown; C old: some leaves already gone, the others still attached, nest still firm and solid; D - very old: holes visible in the nest structure; or $\mathrm{E}$ - almost gone: a few twigs and branches, original nest shape no longer evident $[11,12]$. We are also record the nest position, $\mathrm{A}$ - in the bough of the trees; $\mathrm{B}$ - on a branch limb extending out from the bole; $\mathrm{C}$ - integrated nests and $\mathrm{D}-$ in the apex of the tree branches.

\section{Bear and aging sign}

Proof of target animal's presence: claws, insects feeding, etc., and it will also include the distinguishing bear and aging sign [13]. For the purpose of the possibility on both the Orangutan and Malayan Sun Bear, in terms of termites feeding, the proof can easily distinguish also documented, as possible to the tree species. Track or print width at the toes was used as the most consistent measure 


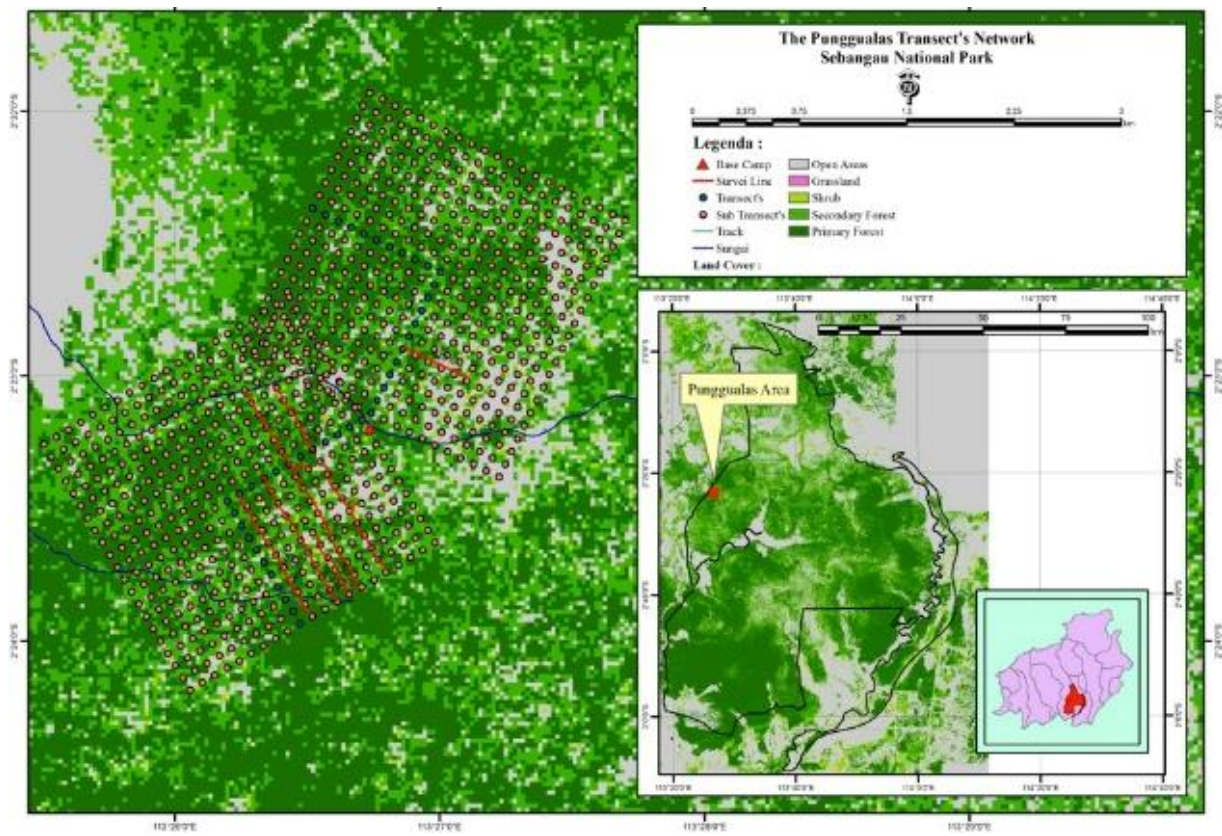

Figure 2. The Study area in Punggualas, Sebangau NP (Inset: Sebangau NP)

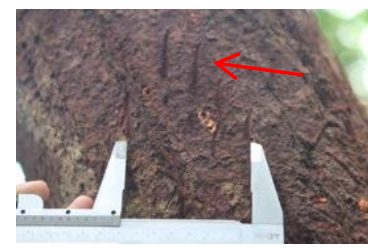

(a)

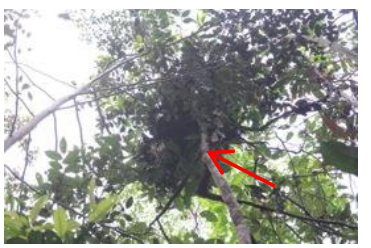

(b)

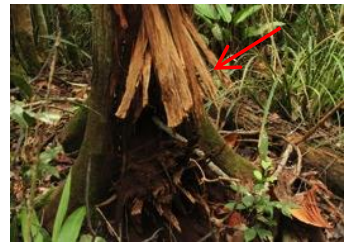

(c)

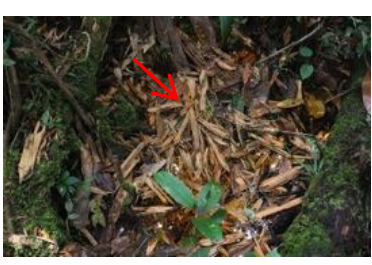

(d)

Figure 3. Target animal proof of presence; a) Sun Bear printed-mark claw; b) Orangutan nest; c) ribbed tree scar by Sun Bear, and d) Orangutan spot on feeding termites (photo-graph by: Adventus Panda, 2019)

because paw length is not present on claw marks in the tree. Means for each set were classified into four general size/age categories as follows: c-cubs (claw marks/prints $<6 \mathrm{~cm}$ width between the center of $1^{\text {st }}$ and $5^{\text {th }}$ digits); j- juvenile or small adult (claw marks/prints $6-6.9 \mathrm{~cm}$ width between the center of $1^{\text {st }}$ and $5^{\text {th }}$ digits) and m: medium-sized adult (claw marks/prints $7-8.9 \mathrm{~cm}$ width between the center of $1^{\text {st }}$ and $5^{\text {th }}$ digits).

\section{Data analysis}

Habitat attributes selected by each species differed by computing means for each attribute on transects with new signs, and testing for differences between species will follow Mann-Whitney $\mathrm{U}$ tests procedure. A relationship between signs uses binary logistic regressions, whereas the coding for presence (1) and absence (0). Habitat Selection models are using binary logistic regressions, the coding for transects is used (1), and $\mathrm{u}$ used (0). Mann-Whitney U Test and binary logis- tic regressions use Analyst Soft Inc., Stat Plus: mac - statistical analysis program for Mac OS, version 2009. Interspecific relationships - if OU and Sun Bear used sites (transects) independently of one another, C-Score should not be different from random, using Co-Occurrence modeling and ESP for Windows. Aside from those measurements, tree species were noted, whether the target animal uses it for claws, nesting site, or even feeding on termites.

\section{Results and Discussions}

A Total of $6580 \mathrm{~m}$ distance along 8 consecutive transects were walked (Figure 3). We randomly selected sub-transects in Northern (two transects) and southern main transects (seven transects) for this preliminary purpose. A total 18 printed mark-claw and 17 Orangutan nests were measured according to the mentioned methodology. For each data measured, such as nest position, nest tree height (m), nest class, and aging sign 


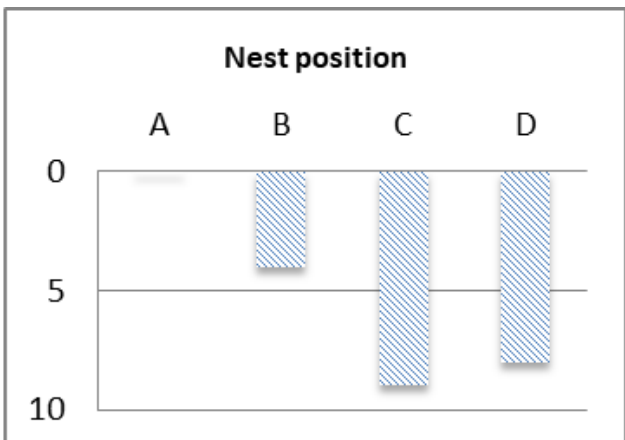

(a)

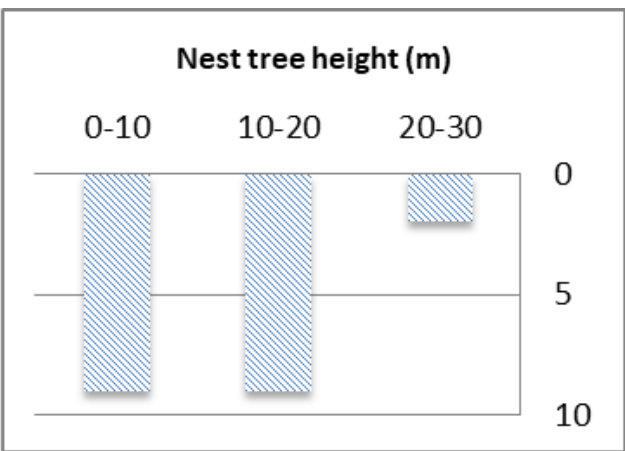

(b)

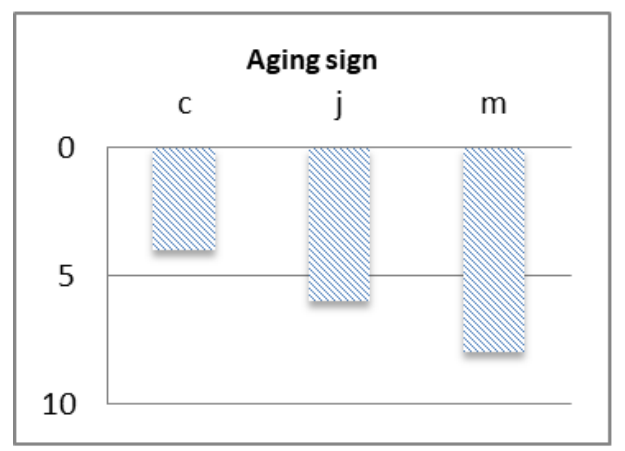

(c)

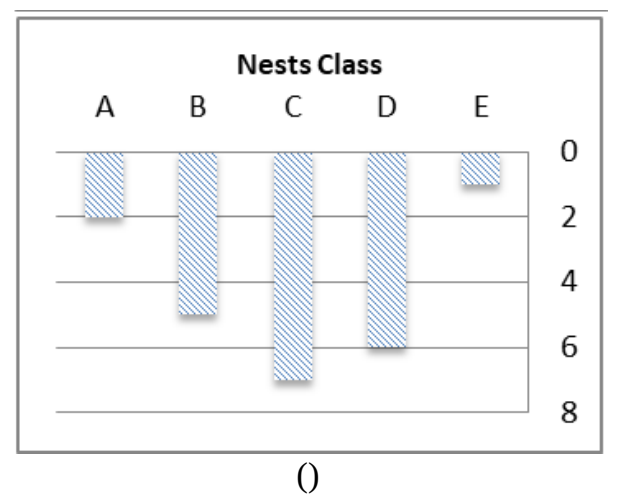

Figure 4. Attributes to the sign of target animal recorded clock-wise order; nest position (a), nest tree height (m) (b), nest class (c), and aging sign (d) (based-on claws size $-\mathrm{cm}$ )
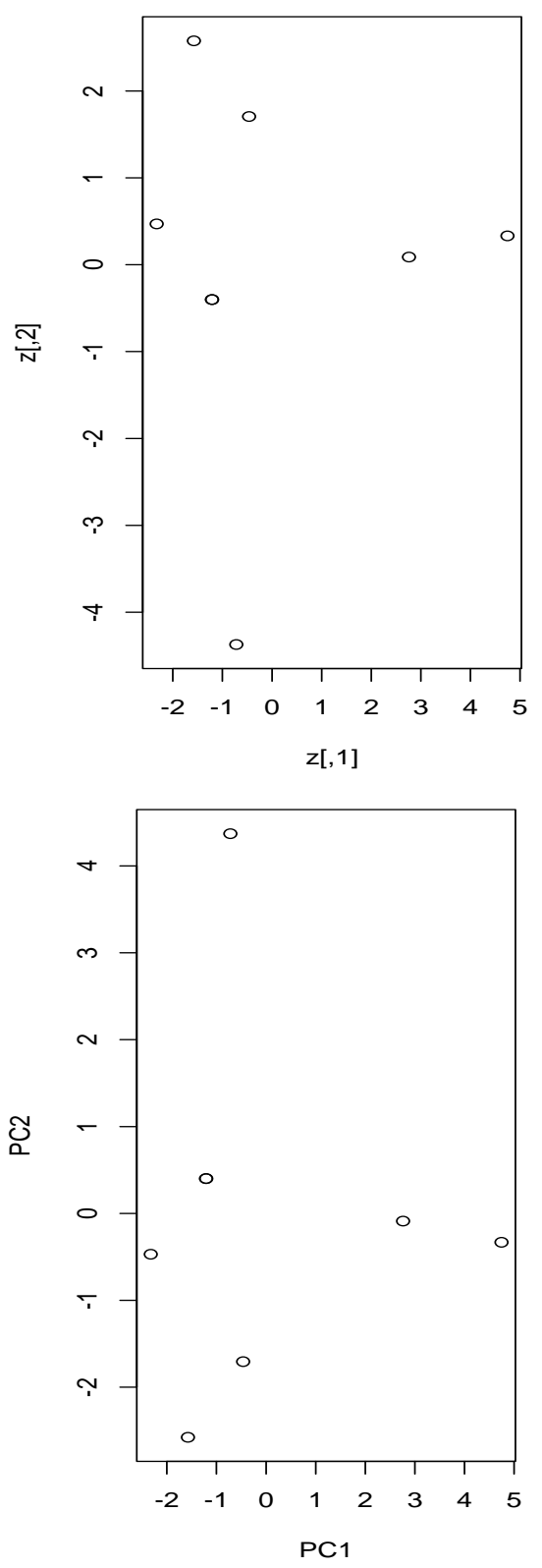

Figure 5. PCA analysis of nest-claws relationship

(based on claws size $-\mathrm{cm}$ ) were plotted in the bar chart shown in Figure 4.

The analysis on relationships between signs showed a significant difference $\left(\chi^{2}=26.249\right.$; $\mathrm{df}: 1$, p-value: 0.001). In other words, presence-absence between the two target animals is not similar since we reject the null hypothesis. This is due to the terrain, whereas the bear sign is the absence in waterlogged terrain in the northern transect, only present in and only dry peat terrain (southern transects). The bear sign revealed to tend to choose specific tree species, such as Horsfieldia grandis $(\mathrm{n}=5)$; Kajunjung $(\mathrm{n}=4)$; Garcinia sp2 $(\mathrm{n}=3)$; 
Madhuca sp. ( $\mathrm{n}=2)$, while the rest species is only spotted one, such as Cratoxylum arborescens and Syzygium sp2. According to the community familiar with traditional botany, these tree species are never entirely in good shape. By means, they tend to have bee cavity (so-called: hamburep - dayak term).

The logistics regression equation is $\mathrm{Y}=-2.079$ $+3.977 \mathrm{x}$. While the results on habitat selection between transects is failed to reject the null hypothesis ( $\chi^{2}=0.29$; df $: 1$, p-value: 0.490$)$, the logistic equation $\mathrm{Y}=-12.37+14.16 \mathrm{x})$. This is confirmed the field findings, whereas bear sign and orangutan nests are very close to each other's.

The PCA-analysis of nest-claws relationships also revealed the same pattern as the Mann-Whitney U Test, which confirmed no distinctive overlap between the Orangutan and the Sun Bear ( $\mathrm{Z}$ : 0.84; p-value: 0.40).

The co-occurrence simulations also revealed significant results $(\mathrm{C}-\mathrm{Score}=1.00)$, by means both target animals co-existed in the habitat. Field observation revealed that the two target animals are in the same tree species $(n=2)$, while the Orangutan nesting on a branch limb extending out from the bole of $H$. grandis tree, while the Sun Bear printed mark-claw below. Another confirmation was revealed the co-occurrence from the feeding sites, indicates by feeding on termites from C. corniculata logs $(\mathrm{n}=9)$. At the same time, the bear rip out the $H$. grandis standing trees close by. Nevertheless, the nest tree heights data also revealed the Orangutan nesting to a range of $0-20 \mathrm{~m}(\mathrm{n}=$ 18). According to another study, many tropical rainforests experience seasonally variable fruit production that influences mammalian frugivore and granivore communities that depend on such forests [14]. They also add information on other related research, including these effects, ranging from reduction in population size, changes in home-range size, seasonal movement, and nomadic behavior and, in extreme cases, mass starvation, extreme famine, and even mass mortality. It is obvious that the Orangutan and Sun Bear occupy the same habitat. There is no distinctive overlap between the main tree species selection and having close interrelationships in terms of feeding ground, whereas the fruiting is not available. The only distinctive difference is that the Bear sign tended to hinder waterlogged terrain.

\section{Conclusion}

The orangutan and the malayan sun-bear apparently share the habitat occupancy, having no distinctive overlap in feeding ground. However, the bear is tending to hinder the waterlogged terrain. It is suggested to enlarge the study, including the difference in seasons shifting and different terrain, with the detailed parameters to confirm these pre liminary findings

\section{Acknowledgment}

We would like to thank Sebangau National Park Authority as a WWF-Indonesia Partners in Sebangau Conservation Project. We would also thank to Yuliansyah and Andi Liani (Karuing Village) for good data keeping in the field.

\section{References}

1. Shepherd PA, Rieley JO, and Page SE (1997) The relationship between forest structure and peat characteristics in the upper catchments of the Sungai Sebangau, Central Kalimantan. Biodiversity and Sustainability of Tropical Peatlands, JO Rieley and SE page (eds). Samara Publishing, Cardigan, UK. Pp. 191-210.

2. Husson SJ, Limin SH, Adul et al. (2018) Biodiversity of the sebangau tropical peat swamp forest, Indonesian Borneo. Mires Peat. doi: 10.19189/MaP.2018.OMB.352

3. Wich SA, Gaveau D, Abram N et al. (2012) Understanding the Impacts of Land-Use Policies on a Threatened Species: Is There a Future for the Bornean Orang-utan? PLoS One. doi: 10.1371/journal.pone.0049142

4. Husson S, Morrogh-bernard H (2004) Orang-utan population dynamics in the Sebangau Ecosystem , Central Kalimantan Distribution, Population Size and Trends. (June): 1-18. OuTrop-WWF Report. outrop@yahoo.co.uk. Pp1-18

5. Santika T, Ancrenaz M, Wilson KA et al. (2017) First integrative trend analysis for a great ape species in Borneo. Sci Rep. doi: 10.1038/s41598-017-04435-9

6. Morrogh-Bernard HC (2008) Fur-rubbing as a form of self-medication in Pongo pygmaeus. International Journal of Primatology 29 (4): 1059-1064. doi: 10.1007/s10764-008-9266-5.

7. Scotson L, Fredriksson G, Augeri D et al. (2017) Helarctos malayanus (errata version published in 2018). The IUCN Red List of Threatened Species 2017: eT9760A123798233 8235 1-26.

8. Wong S Te (1997) The ecology of the Malayan Sun Bear (Helarctos malayanus) the the lowland tropical rainforest Sabah, Malaysian Borneo. Master Thesis, School of Forestry - The University of Montana.

9. Te Wong S, Servheen CW, Ambu L (2004) Home range, movement and activity patterns, and bedding sites of Malayan sun bears Helarctos malayanus in the Rainforest of Borneo. Biological Conservation 119 (2): 169-181. doi: 10.1016/j.biocon.2003.10.029.

10. Cheyne S, Rowland D, Höing A, Husson S (2013) How 
orang-utans choose where to sleep: comparison of nest site variables. Asian Primates Journal 3 (1): 13 - 17.

11. Prasetyo D, Utami S, Suprijatna J (2012) Nest Stuctures in Bornean Orangutan. Jurnal Biologi Indonesia 8 (2): 217-227. doi: 10.14203/jbi.v8i2.3042.

12. van Schaik CP, Priatna A, Priatna D (1995) Population Estimates and Habitat Preferences of Orangutans Based on Line Transects of Nests. Neglected Ape. doi: 10.1007/978-1-4899-1091-2_15

13. Augeri DM (2005) On the Biogeographic Ecology of the
Malayan Sun Bear, Wildlife Research Group, Department of Anatomy, Faculty of Biological Sciences, University of Cambridge. Doctoral Thesis, Faculty of Biological Sciences - University of Cambridge.

14. Siew TW, Servheen C, Ambu L, Norhayati A (2005) Impacts of fruit production cycles on Malayan sun bears and bearded pigs in lowland tropical forest of Sabah, Malaysian Borneo. Journal of Tropical Ecology 21 (6): 627639. doi: 10.1017/S0266467405002622. 